https://helda.helsinki.fi

\title{
Self-determination theory and the collaborative assessment and management of suicidality
}

\section{Holmström, Edua}

2020-01-29

Holmström , E 2020 , ' Self-determination theory and the collaborative assessment and management of suicidality ' , The mental health review , vol. 25 , no. 1 , pp. 75-83 . https://doi.org/10.1108/MHRJ-09

http://hdl.handle.net/10138/327270

https://doi.org/10.1108/MHRJ-09-2019-0029

acceptedVersion

Downloaded from Helda, University of Helsinki institutional repository.

This is an electronic reprint of the original article.

This reprint may differ from the original in pagination and typographic detail.

Please cite the original version. 


\title{
SELF-DETERMINATION THEORY AND THE COLLABORATIVE ASSESSMENT AND MANAGEMENT OF SUICIDALITY
}

\author{
Édua Holmström \\ Faculty of Medicine \\ Postgraduate Professional Education \\ University of Helsinki \\ Helsinki, Finland
}

\begin{abstract}
Purpose: The Collaborative Assessment and Management of Suicidality (CAMS) is a firstencounter suicide-specific brief intervention that motivates suicidal individuals for voluntary treatment engagement and choosing life. How the intervention works, however, has not been theoretically explained. The purpose of this paper is to explain the effectiveness using selfdetermination theory (SDT).
\end{abstract}

Design/methodology/approach: I focus the theoretical examination on the philosophy of care and the clinical procedures of the CAMS suicide intervention. SDT is used as the theoretical lens of the examination.

Findings: The underlying philosophy of care and the clinical procedures of CAMS enhance the autonomy, relatedness and competence of the client in the first encounter. I propose that fulfilling these basic human needs results in the intervention outcomes of treatment engagement and choosing life for the time being.

Research limitations/implications: The research is limited to the examination of the documented clinical procedures and philosophy of care. Further research applying SDT to the design of therapeutic interventions for suicide prevention is warranted.

Practical implications: Clinicians working with suicidal clients need to empathically address suicidal individuals' motivation to engage in voluntary treatment and reduce controlling and autonomy-thwarting approaches.

Social implications: Suicidal behaviour is conventionally considered the manifestation of a mental disorder characterized by limited informed decision-making. The success of CAMS points to the contrary. Despite their suffering, many suicidal individuals make informed decisions about treatment with the support of an empathetic clinician.

Originality/value: CAMS has not previously been theoretically explained. I explain the effectiveness of the intervention in engaging suicidal clients in further treatment through SDT.

Key words: Suicidality, Self-determination theory, Treatment engagement 


\section{Introduction}

Suicide prevention lacks a preventive, strategic framework due to the limited theoretical understanding of its working mechanisms (Calear et al., 2016, De Silva et al., 2013). There is evidence for the efficacy of therapeutic interventions for self-harm behaviour (Ougrin et al., 2015). While suicide-specific interventions show a reduction in suicidal ideation (Calear et al., 2016), these have not been examined to discover the mechanisms that deliver the desired therapeutic changes. While motivation is clearly one of the most essential of these mechanisms, the engagement of suicidal clients on the first clinical encounter is still a neglected aspect of the research (Lizardi \& Stanley, 2010).

The Collaborative Assessment and Management of Suicidality (CAMS) is a suicide-focused intervention for assessing, treating and tracking suicidality, which was developed based on theoretical work on suicidal cognition. It uniquely combines a thorough assessment with a client-centred therapeutic framework, which over the years has gathered considerable evidence of effectiveness (Jobes, 2016). CAMS is associated with a reduction of distress and an increase in treatment satisfaction and hope, as well as higher retention (Comptois et al., 2011), a reduction in suicidal ideation (Jobes et al., 2016, 2017), a decrease in emergency department visits (Jobes et al., 2005), and decreased suicide attempts and self-harm behaviours (Andreasson et al., 2016). A recent study comparing CAMS and dialectical behaviour therapy (DBT) found that DBT is not superior to CAMS for the reduction of suicide attempts (Andreasson et al., 2016).

The mechanisms of how CAMS works to engage and ally suicidal patients in the field extend beyond the theoretical premises on which it was developed. The effectiveness of the intervention has never been explained in light of a coherent theoretical framework. This paper examines the effectiveness of CAMS through working mechanisms derived from selfdetermination theory (SDT) (Ryan and Deci, 2008).

\section{Basic need theory and CAMS}

SDT is a meta-theory of human motivation, self-regulation and personality that cumulatively developed from the seminal work of Richard Ryan and Edward Deci over the years (Ryan and Deci, 2000, 2017; Vansteenkiste et al., 2010). The theory is applied in fields such as health promotion (Ryan et al., 2008), work (Gagné and Deci, 2005), sport and physical exercise (Ryan and Deci, 2017), attachment and close relationships (La Guardia et al., 2000), and psychotherapy (Ryan and Deci, 2017). SDT has more recently been used to explain the 
mechanisms of the development of suicidal ideation through the thwarted satisfaction of our basic psychological needs of belongingness and autonomy (Tucker et al., 2014).

An important part of SDT is the basic need theory that specifies the innate psychological nutrients necessary for motivation and psychological health (Vansteenkiste et al., 2010). It proposes the three basic human needs of autonomy, relatedness and competence and specifies the following three dimensions of the social environment that support these needs: an autonomy-supportive context supports autonomy, a well-structured context supports competence, and an accepting, empathic context supports relatedness.

Regarding psychological interventions, SDT maintains that the extent to which the first clinical encounter supports the three basic needs of autonomy, relatedness and competence will determine the level of engagement of the client (Ryan and Deci, 2008). More specifically, SDT maintains that when patients' autonomy is supported in the therapeutic process, they will be more likely to engage in behavioural change, leading to more positive outcomes. On the other hand, when patients experience conflict with the therapist or pressure for certain outcomes, they will feel externally controlled, and their motivation for changes in the direction of health will be curbed (Ryan and Deci, 2008).

Jobes developed CAMS to address the unmet needs of the suicidal patient, namely, the need for empathy with the suicidal wish and the need for being understood and accepted in a state of high ambivalence. The approach conceptualizes suicide differently from conventional medical approaches in its emphasis on enhancing therapeutic alliance, empathy with the suicidal wish and active engagement of the client in the creation of an outpatient treatment plan. While explicitly client-centred, it diverges from the traditional client-centred approach in that it has a structure and protocol. (Jobes, 2016)

CAMS views ambivalence as a defining characteristic and essential underlying psychological experience of suicidal individuals who seek help in clinical settings (Bergmans et al., 2017; Linehan, 1993). On the one hand, patients have reasons that keep them alive; on the other hand, patients simultaneously feel that suicide is the solution to end their immense pain and suffering. A resolution acknowledges both sides of the inner conflict and the patient's right to die by suicide (Jobes, 2016). This position may provoke and make many clinicians uncomfortable, especially when working with underage patients. However, experts claim that it creates the best possible conditions for engaging suicidal patients in clinical care (Michel and Jobes, 2010; Orbach, 2001). Jobes (2016) identifies the negotiation of putting off suicide 
to a later point in time as the most powerful clinical intervention with a suicidal person who sees the option of coping indefinitely with their perceived pain and suffering as highly unreasonable. Instead, the clinician using CAMS suggests to the suicidal patients that, before they take their life and end their suffering, they give treatment a reasonable chance with the aim of finding other ways of coping.

Although the focus of attention of SDT-anchored research has been mainly on autonomy support, efficient therapeutic encounters should satisfy all of the basic needs of humans. The therapist's warmth and unconditional positive regard, as well as their genuine interest in the patient, conveys a relatedness that, according to the SDT theory, works as an essential nutriment to engagement. The need for competence is connected to the feeling of self-efficacy with respect to an autonomously selected goal. Structure and relevant feedback in the therapeutic environment facilitates fulfilment of the need for competence in the client (Ryan and Deci, 2017).

\section{CAMS: Clinical procedures}

In the following, I present only a short overview of the clinical procedures. A detailed discussion of CAMS is found in Jobes (2016).

The use of a multipurpose tool called the Suicide Status Form (SSF) is central to the approach. The SSF consists of four parts: Sections A, B, C and D. Sections A and B are assessments conducted in close interaction with the patient.

Section A explores deeply subjective experiences such as psychological pain, suffering, and hopelessness. The emphasis in Section A is on delving into the subjective experiences of the patients through the use of a structured assessment process, and it does not focus on suicide per se. This section was built on Baumeister's work on suicide as an escape from the self (1990), Shneidman's concept of psychache referring to psychological pain (1993), and Beck's cognitive therapy for depression (1979).

Section B concentrates on the objective assessment of specific suicidal risk factors and warning signs, thereby providing some objective perspective on various suicide-related variables, such as suicide ideation, plan, rehearsal, and history of suicidal behaviours. The clinician asks the patients in a matter-of-fact manner about the different suicide-related risk factors as specified by previous research (Linehan, 1993; Rudd et al., 2004; Maltsberger, 1986). 
Section C consists of writing the Stabilization and Treatment Plan, whereas Section D is filled out by the clinician after the session, providing information required by the HIPAA.

An important feature of CAMS with respect to SDT is the order of the CAMS sections A-D. The theoretical premise is that enhancing the feelings of autonomy, relatedness and competence at the beginning of the encounter is paramount. The emphasis of Section A is expressly meant to communicate to patients that they are the experts of their own experience. Here, the clinician's job is to see the suicidal risk through the eyes of the patient, focusing on the patient's phenomenology and intra-subjective suicidal struggle. At its best, the initial SSF assessment makes a lasting and important impression: "I am genuinely interested in understanding your pain and suffering by seeing your world as you experience it." (Jobes, 2016, p. 56)

\section{Autonomy, relatedness and competence support in CAMS}

Next, I detail how CAMS enhances the feelings of autonomy, relatedness and competence of the client, resulting in alliance and a deeper engagement of the patient within his or her own care. To help the reader, italics is used to emphasize SDT-relevant features of the intervention.

Autonomy support is inherent both in the underlying philosophy of the CAMS intervention and throughout the clinical procedures. Within the CAMS approach to care, there is an inherent intention to avoid hospitalization and rely on inpatient care only as the last resort. Outpatient care is in line with the importance of endowing autonomy to the client and supporting self-determination (O’Donoghue et al., 2014; Katsakou et al., 2012).

As for the clinical procedure, autonomy is emphasized before and during the completion of Section A of the SSF. The autonomy-supportive atmosphere is explicitly stated to the patients at the beginning of the procedure by asking directly about and validating suicidal thoughts as possible and understandable thoughts in the face of unbearable pain and suffering. Clients' autonomy is further enhanced by offering the collaborative SSF assessment with the explicit rational of understanding suicidality from the framework of the patient's unbearable suffering (as opposed to interrogating the client about a presumed mental disorder). While recommending the collaborative assessment, the clinician acknowledges the option of suicide for the patient by asking them to give treatment a chance for only a limited period of time: 
"Because I know you suffer deeply, I am only asking that you travel with me for a specific period of time, a minimum of 3 months. After that, we can decide together whether we should continue our travels together or perhaps part ways so that you can drive on your own or perhaps travel with a different navigator. Despite your suffering, I still believe this is a reasonable request to ask of you, given both the promise of our desired destination and the seriousness of the alternative you are considering" (Jobes, 2016, p. 78).

Validating the client's right to decide upon his or her life is regarded by Jobes as one of the most essential components of CAMS (2016). Once the client agrees to do the SSF, the clinician continues with autonomy support by not taking anything for granted, i.e., by asking for permission to take a sit next to the client to complete the Suicide Status Form together. Autonomy is further enhanced by making sure that the patient is informed about the name and usefulness of the procedure and by asking the client to take the pen themselves to fill out the first part of the assessment, while emphasizing the role of the clinician as a coach or a consultant who helps and support if the client needs it. Autonomy is also marked by asking patients to determine themselves what they find most painful, most stressful and most hopeless in their life and to give reasons for their wish to die which are subsequently met with empathy as opposed to judgement and confrontation.

After finishing Section A and while moving to Section B, the clinician continues supporting the client's autonomy by repeating once more the rationale for completion: to gain a better understanding about the pain and suffering that led the patient to feeling suicidal, with the aim of alternative ways of coping with the pain and suffering of the patient.

Finally, patients are themselves the co-authors of their stabilization and treatment plan, thereby endowing them with a further sense of autonomy. At the end of the assessment part, clients are informed about the clinician's appreciation of their choice of sharing their painful experiences, and the clinician thanks the client for their collaboration, indicating respect for the client as a subject with agency, whose collaboration is not taken for granted.

Support for the need for competence is accommodated above all by the inherently collaborative nature of the CAMS protocol that creates an essential synergy that is the backbone of the approach. The patient is considered an expert on his or her situation who can give an account of the reasons that led to a suicidal state. This subjective account is validated as a reasonable psychological response to unbearable pain. Competence is further enhanced 
by telling the client that the clinician's role is to follow and support, to work as a coach, to be a collaborator, and to clarify and assist if needed.

The competence of the patient is also marked by their sitting next to the clinical worker and by filling out the paper himself/herself and marking his/her expertise on the subject (instead of sitting opposite to and being interrogated by a worker of institutionally vested authority, as is often the case in an emergency setting). Writing the answers themselves, the clients rate their level of psychological pain, stress, agitation, hopelessness and self-hate and give an evaluation of their overall risk for suicide. Their feeling of competence is further enhanced by rank-ordering these factors in terms of importance. Clients' competence in their suicidality is further enhanced by asking them to give their reasons to live and reasons to die and by asking them to rank-order these reasons in terms of importance. Furthermore, clients are asked to report the extent to which they wish to live and wish to die and to give information on the one thing that would make them non-suicidal.

In addition to the informational content that the client provides about their own suicidality, the very structured nature of CAMS with both self-rating and open-ended questions further facilitates the feeling of competence of the client. Structure enhances self-regulation and task engagement and provides a clearer view of the steps to succeed (Guay et al., 2017; Mouratidis et al., 2012). The importance of providing structure to enhance competence has been widely recognized in clinical and health-related interventions (Linehan, 1993; Rudd et al., 2004) and can be explained in light of SDT (Ryan and Deci, 2017).

Managing the client's suicidality in CAMS fundamentally relies on what the patient says puts his or her life in peril. Rather than relying on a mental disorder diagnostic bias or using an a priori theoretically driven treatment model, the CAMS approach directly turns to the client who is assumed to most intimately know about the suicidal struggle. It is the client who knows what problems, issues, or concerns most make them want to take their life.

Subsequently, when patients come to realize that their view of things are actually central to the CAMS treatment planning, they often become engaged because of the truly pivotal role they play in the development of their own treatment plan. As a co-author of their treatment plan, it is interesting to see how quickly many suicidal patients latch on to the idea of targeting and treating their suicidal drivers (Jobes, 2016, p. 76). 
As a client-centred approach, the support of relatedness is inherent in the CAMS procedure in its emphasis on a genuine interest in the client's subjective experience, unconditional positive regard, and empathy with the suicidal wish. Relatedness is enhanced from the beginning of the first session, when clinicians address suicidality without a hint of judgement, by making it clear that they hear and see that the patient is extremely overwhelmed by pain and suffering.

As the session unfolds, relatedness is expressed when the clinician justifies the assessment as a way of helping them to better understand the situation of the patient. Relatedness is further enhanced by the clinician by sitting next to the patient and by offering to be similar to a coach who follows, supports, and helps in case the patient needs it. The sense of relatedness is maintained during the time the client fills out the SSF core assessment.

Upon finishing Section A, the clinician again expresses the importance of the client's sharing of his/her experience, leading to a better understanding of the part of the clinician. The clinician expresses to the client that his/her enhanced understanding of the client's perspective allows them to come up with a workable treatment plan for effectively dealing with the client's pain and suffering.

The language of the clinician, as Jobes describes it (2016), is outstandingly relatednesssupportive during the entire CAMS process. Relatedness is manifested by the invitation for true collaboration and by an open, accepting and non-judgemental attitude on the part of the clinical worker. The clinician talks in first-person plural (we) and emphasizes the treatment as being a common journey to which they both commit themselves and in which the clinician will accompany and support the patient all along.

Upon moving to Section B, the clinician remains seated next to the client, marking the continuity of relatedness under the rest of the assessment. In Section $\mathrm{C}$, the clinician uses the metaphor of "the therapeutic road trip" (p. 78), comparing their collaboration to a common journey they take together, marking relatedness as a central element during the entire collaboration:

"I want you to consider taking a therapeutic road trip with me. On this trip you will be the driver and I will be the navigator. I have taken this trip many times before, I know the roads well, and I have excellent maps and a GPS. However, the journey is never the same route for any two drivers. It is unique to the driver and the way we decide to travel together-which roads to take, when to stop, and how fast or slow we decide to go" (Jobes, 2016, p. 78). 


\section{Discussion}

Recent years have renewed the academic interest in person-centred care within mental health settings, exemplified by an interest in shared decision making (Ramon et al., 2017) and recovery-oriented care (Davidson et al., 2017). Assessment is moving away from a diagnostic reductionism towards an experience-based framework that emphasizes self-determination (Binnie, 2018; Binnie and Spada, 2018). However, endowing suicidal individuals with autonomy and relying on their competence to decide for themselves is provocative in many clinical settings (Jobes, 2016).

Suicidal behaviour has traditionally been seen as a manifestation of a mental disorder characterized by a lack of capacity for informed decision-making, which compromises patients' autonomy rights. At the same time, controlling practices are widely used, including psychotropic medications, non-suicidal contracts, and psychiatric hospitalizations for suicidal ideation. However, given the lack of empirical support for these controlling and autonomythwarting approaches, the reliance on them is puzzling (Brodsky et al., 2018). Evidence of the effectiveness of psychotropics is mixed, and inpatient care that is not suicide-specific may even increase post-discharge risk (Linehan et al., 2015). Furthermore, Czcy et al. (2016) noted that the rehospitalisation of suicidal youth increased vulnerability to suicidal crisis. Linehan et al. (2015) contends that contemporary inpatient psychiatric hospitalization has no empirical support for preventing suicide.

Britton et al. (2008) suggested that suicide prevention techniques would benefit from the theoretical premises of SDT. Scientific evidence points to the effectiveness of autonomysupportive interventions in detaining patients from suicide (Jobes et al., 2008) More recently, Hill and Pettit (2013) pinpointed autonomy support as an important element in suicide prevention.

The heavy emphasis on relatedness has always been a benchmark of therapeutic work, but its lessons are relatively new in the mainstream assessment of suicidality (Dunster-Page et al., 2017). However, converging evidence shows that psychological assessments that are therapeutic in nature have positive, clinically meaningful effects on treatment, especially regarding the treatment processes. Highlighting the support of SDT's basic needs as the key potential factors of intervention effectiveness also gets support from findings about the role of the thwarted needs of autonomy and relatedness in suicidal ideation (Tucker et al., 2014). The weight of evidence for engaging suicidal patients appears to be consistent with SDT, and thus far, little has been found to contradict or refute it. 
Based on a 10-year systematic review of evidence-based findings in suicide prevention, Brodsky et al. (2018) summarized the areas necessary for translating suicide prevention research into clinical practice. This present study suggests that these guidelines be extended to explicitly address treatment engagement. This should be done by emphasizing the socialinteractional factors of the first clinical encounter that support the client's needs of autonomy, relatedness and competence.

\section{Conclusion}

This study examined an evidence-based suicide prevention intervention, the CAMS, and showed that its constituent elements and unique philosophy of care provide the socialenvironmental factors postulated by SDT to support autonomy, relatedness and competence. I further hypothesized that the support of these three basic needs in the first clinical encounter is responsible for CAMS's effectiveness as a suicide prevention intervention. While not compromising the importance of a thorough assessment and the writing of a safety plan, CAMS gives temporal priority to providing time and space for the clients' subjective feelings and for empathy of the suicidal wish, as well as to understand their reasons for suicide ideation and to detain them from controlling practices.

Both theoretical work on SDT and clinical work with suicidal patients benefit from bridging theory and practice. Connecting theory to practice usually occurs through operationalizing theoretical constructs to apply them in clinical work, thereby leading to cumbersome issues of validity. This study took the opposite road and aimed to highlight the motivational processes that may produce the observed effects of CAMS on detention from suicide. This approach provides clinicians with a concrete example of the application of SDT in their clinical work that can be used in the development and refining of interventions and treatments of suicidality. Similarly, SDT researchers in the academic field may benefit from seeing an interesting set of techniques providing insights on how the support of the three basic needs can be implemented in suicide prevention practice.

The theoretical perspective taken in this study also has its limitations. Taking an explorative perspective has led to a hypothesis explaining the effectiveness of a suicide-specific intervention. Future studies should empirically test this hypothesis by measuring clients' perceived need satisfaction during the CAMS sessions and empirically examine the effects of these factors on quantified measures of treatment motivation, treatment engagement and other therapeutic outcomes, such as reduced dropout and relapse.

\section{References:}


Andreasson, K., Krogh, J., Wenneberg, C., Jessen, H. K., Krakauer, K., Gluud, C., ... \& Nordentoft, M. (2016). Effectiveness of dialectical behavior therapy versus collaborative assessment and management of suicidality treatment for reduction of self-harm in adults with borderline personality traits and disorder-A randomized observer-blinded clinical trial. Depression and anxiety, 33(6), 520-530. http://dx.doi.org/10.1002/da.22472

Baumeister, R. F. (1990). Suicide as escape from self. Psychological review, 97(1), 90-113. http://dx.doi.org/10.1037/0033-295X.97.1.90

Beck, A. T. (Ed.). (1979). Cognitive therapy of depression. Guilford press.

Bergmans, Y., Gordon, E., \& Eynan, R. (2017). Surviving moment to moment: The experience of living in a state of ambivalence for those with recurrent suicide attempts. Psychology and Psychotherapy: Theory, Research and Practice, 90(4), 633-648. http://dx.doi.org/10.1111/papt.12130

Binnie, J., \& Spada, M. (2018). Let's put the "T" back into CBT. Mental Health Review Journal, 23(4), 240-245. http://dx.doi.org/10.1108/MHRJ-02-2018-0002

Binnie, J. (2018). Medical approaches to suffering are limited, so why critique Improving Access to Psychological Therapies from the same ideology. Journal of health psychology, 23(9), 1159-1162. http://dx.doi.org/10.1177/1359105318769323

Brodsky, B. S., Spruch-Feiner, A., \& Stanley, B. (2018). The Zero suicide Model: Applying evidence-Based suicide Prevention Practices to clinical care. Frontiers in psychiatry, 9, 33. http://dx.doi.org/10.3389/fpsyt.2018.00033

Britton, P. C., Williams, G. C., \& Conner, K. R. (2008). Self-determination theory, motivational interviewing, and the treatment of clients with acute suicidal ideation. Journal of clinical psychology, 64(1), 52-66. http://dx.doi.org/10.1002/jclp.20430

Calear, A. L., Christensen, H., Freeman, A., Fenton, K., Grant, J. B., Van Spijker, B., \& Donker, T. (2016). A systematic review of psychosocial suicide prevention interventions for youth. European child \& adolescent psychiatry, 25(5), 467-482. http://dx.doi.org/10.1007/s00787-015-0783-4

Comtois, K. A., Jobes, D. A., S. O'Connor, S., Atkins, D. C., Janis, K., E. Chessen, C., ... \& Yuodelis-Flores, C. (2011). Collaborative assessment and management of suicidality (CAMS): feasibility trial for next-day appointment services. Depression and Anxiety, 28(11), 963-972. DOI MISSING

Czyz, E. K., Berona, J., \& King, C. A. (2016). Rehospitalization of suicidal adolescents in relation to course of suicidal ideation and future suicide attempts. Psychiatric services, 67(3), 332-338. http://dx.doi.org/10.1176/appi.ps.201400252

Davidson, L., Tondora, J., Pavlo, A. J., \& Stanhope, V. (2017). Shared decision making within the context of recovery-oriented care. Mental Health Review Journal, 22(3), 179190. http://dx.doi.org/10.1108/MHRJ-01-2017-0007

De Silva, S., Parker, A., Purcell, R., Callahan, P., Liu, P., \& Hetrick, S. (2013). Mapping the Evidence of Prevention and Intervention Studies for Suicidal and Self-Harming Behaviors in Young People. Crisis, 34(4), 223-232. http://dx.doi.org/10.1027/0227-5910/a000190. 
Dunster-Page, C., Haddock, G., Wainwright, L., \& Berry, K. (2017). The relationship between therapeutic alliance and patient's suicidal thoughts, self-harming behaviours and suicide attempts: A systematic review. Journal of affective disorders, 223, 165-174. http://dx.doi.org/10.1016/j.jad.2017.07.040

Gagné, M., \& Deci, E. L. (2005). Self-determination theory and work motivation. Journal of Organizational behavior, 26(4), 331-362. http://dx.doi.org/10.1002/job.322

Guay, F., Roy, A., \& Valois, P. (2017). Teacher structure as a predictor of students' perceived competence and autonomous motivation: the moderating role of differentiated instruction. British Journal of Educational Psychology, 87(2), 224-240. http://dx.doi.org/10.1111/bjep.12146

Hill, R. M., \& Pettit, J. W. (2013). The role of autonomy needs in suicidal ideation: Integrating the interpersonal-psychological theory of suicide and self-determination theory. Archives of Suicide Research, 17(3), 288-301. http://dx.doi.org/10.1080/13811118.2013.777001

Jobes, D. A. (2016). Managing suicidal risk: A collaborative approach. New York, NY, US: Guilford Press.

Jobes, D. A., Wong, S. A., Conrad, A. K., Drozd, J. F., \& Neal-Walden, T. (2005). The collaborative assessment and management of suicidality versus treatment as usual: A retrospective study with suicidal outpatients. Suicide and Life-Threatening Behavior, 35(5), 483-497. http://dx.doi.org/10.1521/suli.2005.35.5.483

Jobes, D. A., Rudd, M. D., Overholser, J. C., \& Joiner Jr, T. E. (2008). Ethical and competent care of suicidal patients: Contemporary challenges, new developments, and considerations for clinical practice. Professional Psychology: Research and Practice, 39(4), 405.

http://dx.10.1037/a0012896

Jobes, D. A., Comtois, K. A., Brenner, L. A., Gutierrez, P. M., \& O'Connor, S. S. (2016). Lessons learned from clinical trials of the Collaborative Assessment and Management of Suicidality (CAMS). The International Handbook of Suicide Prevention, 431-449. http://dx.doi.org/10.1002/9781118903223.ch24

Jobes, D. A., Comtois, K. A., Gutierrez, P. M., Brenner, L. A., Huh, D., Chalker, S. A., ...\& Crumlish, J. (2017). A randomized controlled trial of the collaborative assessment and management of suicidality versus enhanced care as usual with suicidal soldiers. Psychiatry, 80(4), 339-356. http://dx.doi.org/10.1080/00332747.2017.1354607

Katsakou, C., Rose, D., Amos, T., Bowers, L., McCabe, R., Oliver, D., ... \& Priebe, S. (2012). Psychiatric patients' views on why their involuntary hospitalisation was right or wrong: a qualitative study. Social psychiatry and psychiatric epidemiology, 47(7), 1169-1179. http://dx.doi.org/10.1007/s00127-011-0427-z

La Guardia, J. G., Ryan, R. M., Couchman, C. E., \& Deci, E. L. (2000). Within-person variation in security of attachment: a self-determination theory perspective on attachment, need fulfillment, and well-being. Journal of personality and social psychology, 79(3), 367. http://dx.doi.org/10.1037/0022-3514.79.3.367

Linehan, M. M. (1993). Diagnosis and treatment of mental disorders. Cognitive-behavioral treatment of borderline personality disorder. New York, NY, US: Guilford Press. 
Linehan, M. M., Korslund, K. E., Harned, M. S., Gallop, R. J., Lungu, A., Neacsiu, A. D., ... \& Murray-Gregory, A. M. (2015). Dialectical behavior therapy for high suicide risk in individuals with borderline personality disorder: a randomized clinical trial and component analysis. JAMA psychiatry, 72(5), 475-482.

http://dx.doi.org/10.1001/jamapsychiatry.2014.3039

Lizardi, D., \& Stanley, B. (2010). Treatment engagement: a neglected aspect in the psychiatric care of suicidal patients. Psychiatric Services, 61(12), 1183-1191. http://dx.doi.org/10.1176/ps.2010.61.12.1183

Maltsberger, J. T. (1986). Suicide risk: The formulation of clinical judgment. New York, NY, US: New York University Press.

Michel, K., \& Jobes, D. A. (2010). Building a therapeutic relationship with the suicidal patient. Washington, DC, American Psychological Association. http://dx.doi.org/10.1037/12303-000

Mouratidis, A., Vansteenkiste, M., Michou, A., \& Lens, W. (2012). Perceived structure and achievement goals as predictors of students' self-regulated learning and affect and the mediating role of competence need satisfaction. Learning and Individual Differences, 23, 179-186. http://dx.doi.org/10.1016/j.lindif.2012.09.001

O'Donoghue, B., Roche, E., Shannon, S., Lyne, J., Madigan, K., \& Feeney, L. (2014). Perceived coercion in voluntary hospital admission. Psychiatry research, 215(1), 120-126. http://dx.doi.org/10.1016/j.psychres.2013.10.016

Orbach, I. (2001). Therapeutic empathy with the suicidal wish: Principles of therapy with suicidal individuals. American Journal of Psychotherapy, 55(2). http://dx.doi.org/10.1176/appi.psychotherapy.2001.55.2.166

Ougrin, D., Tranah, T., Stahl, D., Moran, P., \& Asarnow, J. R. (2015). Therapeutic interventions for suicide attempts and self-harm in adolescents: systematic review and metaanalysis. Journal of the American Academy of Child \& Adolescent Psychiatry, 54(2), 97-107. http://dx.doi.org/10.1016/j.jaac.2014.10.009

Ramon, S., Brooks, H., Rae, S., \& O'Sullivan, M. J. (2017). Key issues in the process of implementing shared decision making (DM) in mental health practice. Mental Health Review Journal, 22(3), 257-274. http://dx.doi.org/10.1108/MHRJ-01-2017-0006

Rudd, M. D., Joiner, T. E., \& Rajab, M. H. (2004). Treating suicidal behavior: An effective, time-limited approach. New York, NY, US: Guilford Press.

Ryan, R. M., \& Deci, E. L. (2000). Self-determination theory and the facilitation of intrinsic motivation, social development, and well-being. American Psychologist, 55(1), 68-78. http://dx.doi.org/10.1037/0003-066X.55.1.68

Ryan, R. M., \& Deci, E. L. (2008). A self-determination theory approach to psychotherapy: The motivational basis for effective change. Canadian Psychology/ Psychologie canadienne, 49(3), 186-193. http://dx.doi.org/10.1037/a0012753

Ryan, R. M., \& Deci, E. L. (2017). Self-determination theory: Basic psychological needs in motivation, development, and wellness. Guilford Publications. 
Ryan, R. M., Patrick, H., Deci, E. L., \& Williams, G. C. (2008). Facilitating health behaviour change and its maintenance: Interventions based on self-determination theory. European Health Psychologist, 10(1), 2-5.

Shneidman, E. S. (1993). Suicide as psychache: A clinical approach to self-destructive behavior. Lanham, MD, US: Jason Aronson.

Tucker, R. P., \& Wingate, L. R. (2014). Basic need satisfaction and suicidal ideation: A selfdetermination perspective on interpersonal suicide risk and suicidal thinking. Archives of Suicide Research, 18(3), 282-294. http://dx.doi.org/10.1080/13811118.2013.824839

Vansteenkiste, M., Niemiec, C. P., \& Soenens, B. (2010). The development of the five minitheories of self-determination theory: An historical overview, emerging trends, and future directions. In The decade ahead: Theoretical perspectives on motivation and achievement (pp. 105-165). Emerald Group Publishing Limited. http://dx.doi.org/10.1108/S0749-

7423(2010)000016A007 